\title{
Genotoxic and Biological Evaluation of a Nano Silica Cross Linked Composite Specifically Used for Intra-Vas Device
}

\author{
Shu-Jian Chen', Yao Bai ${ }^{2}$, Xun-Bin Huang ${ }^{1 *}$, Jin-Ping Suo ${ }^{3}$, Juan $\mathrm{Li}^{3}$ \\ ${ }^{1}$ Family Planning Research Institute, Tongji Medical College, Huazhong University of Science and Technology, Wuhan, China; ${ }^{2}$ Wuhan \\ Institute of Environmental Medicine, School of Public Health, Tongji Medical College, Huazhong University of Science and Tech- \\ nology, Wuhan, China; ${ }^{3}$ State Key Laboratory of Mould Technology, College of Materials Science and Engineering, Huazhong Uni- \\ versity of Science and Technology, Wuhan, China. \\ Email: "huangxb@mails.tjmu.edu.cn
}

Received November $25^{\text {th }}, 2011$; revised January $5^{\text {th }}, 2012$; accepted January $16^{\text {th }}, 2012$

\begin{abstract}
The Context: Aims: To evaluate the biocompatibility and in vitro genotoxicity of a non-copper nano silica polymer modified composite for filtering-type intra-vas devices. Settings and Design: Academic research laboratory, Huazhong University of Science and Technology. Prospective experimental study. Methods and Material: Non-copper nano silica polymer modified composite rods were implanted into the back muscle of rabbits for biocompatibility evaluation. Comet assay was applied to the determination of DNA damage, while, Mutagenic activity was tested by means of Ames test using Salmonella typhimurium TA98 and TA100 tester strains with and without metabolic activation. Statistical analysis used: qualitative and quantitative data were tested using the Chi-square test and Student's test. Results: Only mild inflammatory reaction was observed in the surrounding tissues of the implanted nano-silica modified polymer composite in the early implantation stage, which was similar to that of the sham-operated group. The inflammatory reaction was completely disappeared after 12 weeks. No significant DNA damage $(P>0.05)$ was tested on the nano-silica modified polymer composite in Comet assay. In Ames test, the extracts from non-copper composite did not exert mutagenic effect on the bacterial. Conclusions: The non-copper nano silica modified composite did not exhibit in vitro genotoxicity and obvious inflammation in tissue, it would be a safe biomaterial for further clinical trial.
\end{abstract}

Keywords: Nano; Silica; Genotoxicity; Biocompatibility; Intra-Vas Device; Composite

\section{Introduction}

Filtering-type intra-vas devices (IVD) as possible alternatives of vasectomy have been attracted researchers to keep exploring new configurations and novel biomaterials for it $[1,2]$. Recent reports exhibiting that copper ions may have genotoxicity on mammalian cells [3-5] prompted us to improve constitutes of the novel contraceptive composite specifically suitable for filtering-type IVDs. In the previous study, we did not find significant changes of copper ions in dog's semen after the copper-containing composite IVD implanted for 12 months [2], so copper ions in the composite may not be a necessary. By keeping the characteristics of filtering function and all other components of the composite except copper chloride, we produced the non-copper microporous polymer composite and tested on its biocompatibility and genotoxicity to meet the harsh requirement for clinical

"Corresponding author. trial.

\section{Subjects and Methods}

\subsection{Chemicals}

The PVA used in the study was supplied by Shanxi Sanwei Group Co. Ltd., China (polymerization 2400 and where colloid particles are dispersed homogeneously in water, provided by the Secondary Chemical Factory of Wuhan, China. The content of silica is $30 \mathrm{wt} \%$ and the particle size is about $10 \mathrm{~nm}$ degree of hydrolysis $\sim 99 \%$ ). Silica sol is a colloid solution.

Fetal bovine serum(FBS) was from Gibco and Trypan blue were obtained from Sigma (St. Louis, MO, USA), dimethyl sulfoxide (DMSO) and ethidium bromide (EB) were procured from Amresco (Solon, OH, USA). Parenzyme was from Amresco (Solon, OH). All other reagents, of analytical grade or higher, were purchased from Shanghai Chemical Company (Shanghai, China), unless 
otherwise noted.

\subsection{Cell Line}

The TM4 cell line was purchased from the American Type Culture Collection (CRL-1715, ATCC, Manassas, VA). These cells derived from Sertoli cells of murine testis, represent an appropriate cell model to investigate the link between toxicity of contraceptive material and reproductive system.

\subsection{Nano-Silica Modified Polymer Composite and IVD Prototype}

\subsubsection{Preparation of Non-Copper Composite}

The preparation of PVA solution: aqueous $10 \mathrm{wt} \% \mathrm{PVA}$ solutions were prepared by soaking pre-weighed quantities of dry PVA in de-ionized water for $6 \mathrm{~h}$ and heating at $90^{\circ} \mathrm{C}$ for $1 \mathrm{~h}$. The modification of PVA: silica sol was then mixed with the previously prepared PVA solution by stirring at $80^{\circ} \mathrm{C}$ for $1 \mathrm{~h}$ to obtain a homogeneous solution. PVA was modified by silica to decrease its solubility and enhance its mechanical properties. The mixture was continuously stirred at $50^{\circ} \mathrm{C}$ for $0.5 \mathrm{~h}$. After that, the mixture was poured into a clean and slick glass plate and placed in the ventilation cupboard for about 2 days to allow the solvent to evaporate.

Producing of the Filtering-Type IVD Prototype

Except for mixing of copper chloride, the detailed procedures of producing filtering-type IVD prototype were as described as in our previous study [2]. The specifications of the filtering-type IVD were modified as follow: outer diameter: $0.8-1.0 \mathrm{~mm}$; inner diameter, $0.6-0.7$ $\mathrm{mm}$; thickness, $0.2-0.3 \mathrm{~mm}$; and length, $33 \mathrm{~mm}$. The size, form and hardness of this IVD ensure that it can be easily inserted into the vas through a mini incision. The IVD was patented in 2009 in China (Application No. CN200910301330.3). See Figure 1.

\subsubsection{Preparation of the Extracts}

The non-copper composite sample was first disinfected with ethylene oxide and then put into phosphate-buffered saline solution (PBS) or culture medium supplemented with $10 \% \mathrm{FBS}$, and penicillin-streptomycin solution (100 $\mathrm{U}$ penicillin and $100 \mathrm{mg}$ of streptomycin per $\mathrm{mL}$ ) at the ratio of $1.0 \mathrm{~g}$ sample in $5 \mathrm{~mL}$ solution. After the sample was soaked for 24 hours in a $37^{\circ} \mathrm{C}$ incubator, the solution was disinfected and stored at $4^{\circ} \mathrm{C}$.

\subsubsection{Implantation Test}

Fifteen healthy adult New Zealand white rabbits (Wuhan University Laboratory Animal Center, China), body weight $3.0-4.0 \mathrm{~kg}$, were employed in the experiment. The animals were divided into three groups of different implantation periods (1, 4, and $12 \mathrm{wk}$ ), with five animals tested at each time period. All animal experimental procedures were carried out in accordance with the Guidelines and Regulations for the Use and Care of Animals of the Review Board of Huazhong University of Science and Technology. Each animal was anesthetized by an intraperitoneal injection of sodium pentobarbital $(30 \mathrm{mg} / \mathrm{kg}$ body weight). The biomaterial was then implanted into the spinal muscle of the rabbits at four points, at $2-\mathrm{cm}$ intervals, and the material inserted into the muscle at a

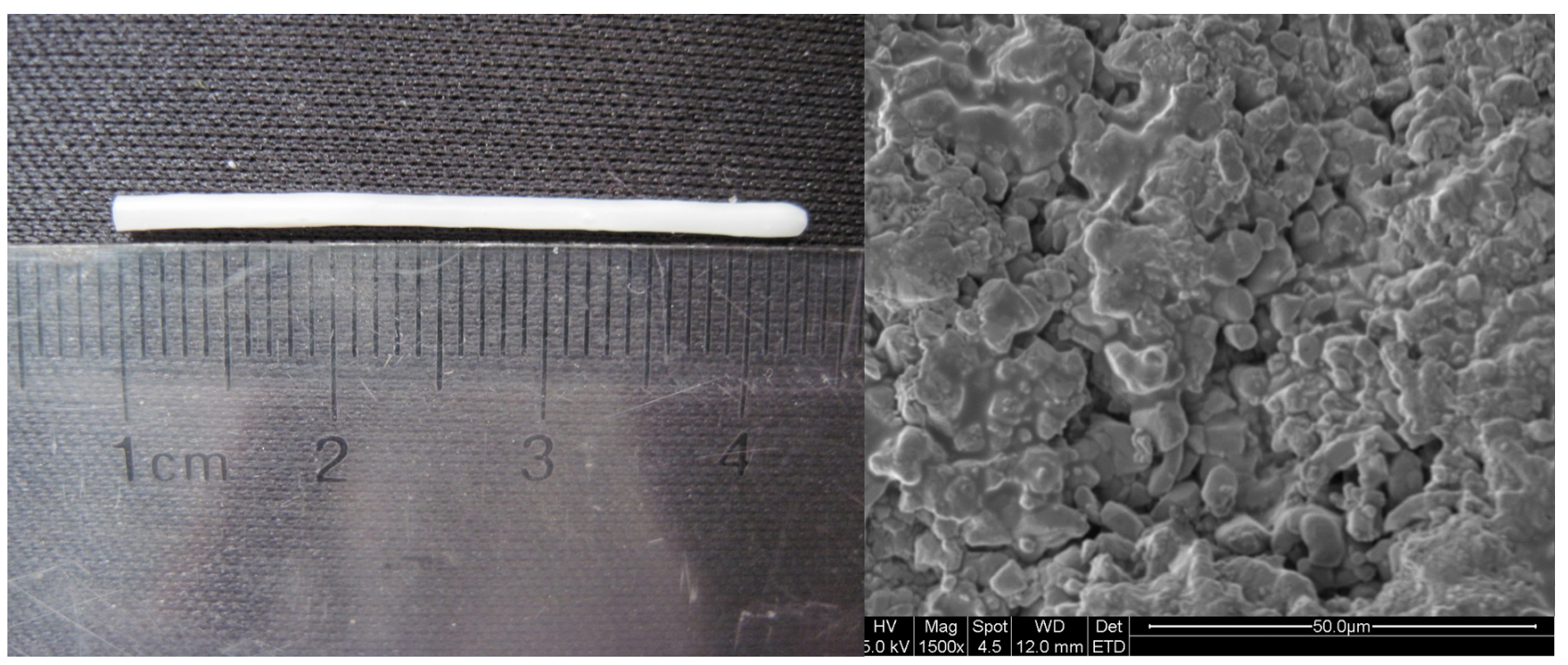

Figure 1. The left figure is the filtering-type IVD prototype of nano-silica modified polymer composite; the right figure showed the microporous wall of the IVD taken by a scanning electron microscope (E.M. × 1500). Irregularly shaped micropores with about $5 \mathrm{\mu m}$ diameters can be seen formed on the wall of the IVD. 
$1-2 \mathrm{~cm}$ in depth. The contralateral side was sham-operated. Rabbits were sacrificed by $\mathrm{CO}_{2}$ asphyxiation sequentially at 1,4 , and 12 weeks after the implantation. Both sites of the spinal muscles adjacent to the nanosilica modified polymer composite were carefully excised from the surrounding tissue and immersed in 10 vol\% buffered formalin solution for 48 hours. The specimens were paraffin embedded. Six-micrometer serial sections were obtained and stained with hematoxylin and eosin. The stained sections were assessed with light microscopy (Olympus, Germany).

\subsubsection{Trypan Blue Exclusion Assay}

To verify whether samples are non-cytotoxic on the basis of MTT, we investigated cell viability of selected concentration suitable for genotoxic evaluation using Trypan blue exclusion assay [6], which was just prior to performing alkaline comet assay. $100 \mu \mathrm{l}$ of cell suspension was mixed with $100 \mu \mathrm{l}$ of Trypan blue $(0.4 \%$, w/v). Thereafter, the viable (transparent) and nonviable (blue) cells were counted by immediate microscopic observation using a hemocytometer.

\subsubsection{Alkaline Single Cell Gel Electrophoresis Assay}

Comet assay is a versatile, sensitive, and rapid method for measuring DNA single- and double-strand breaks at the level of individual cells and is the most frequently used genotoxicity test for chemicals. As described by [7], TM4 cell samples were suspended in $0.7 \%$ low melting agarose $(100 \mu \mathrm{l})$ and applied to the prepared slides. Then slides were immersed in prechilled lysis buffer $(2.5 \mathrm{M}$ $\mathrm{NaCl}, 100 \mathrm{mM} \mathrm{Na} 2$ EDTA, $200 \mathrm{mM} \mathrm{NaOH}, 10 \mathrm{mM}$ Trisbase, $1 \%$ TritonX-100, and 10\% DMSO) for $1.5 \mathrm{~h}$. Following a 20-min DNA unwinding period, the electrophoresis was performed in alkaline buffer for $25 \mathrm{~min}$. After neutralization in 0.4 M Tris-base buffer ( $\mathrm{PH} 7.5)$, cells were stained with ethidium bromide $(20 \mu \mathrm{g} / \mathrm{mL})$. At least 150 cells per concentration were randomly selected and captured at $200 \times$ magnification using fluorescence microscope Olympus BX51 (Olympus, Tokyo, Japan) equipped with an Olympus DP71 (Olympus, Tokyo, Japan) digital color camera. For quantitative analysis, Comet assay software project, CASP software [8] was utilized, and the Olive Tail Moment (OTM), preconised by Olive [9], was chosen to characterize DNA damage in individual cells.

\subsubsection{Ames Test}

Two tester strains, TA98 and TA100, were supplied by the laboratory of Dr. B. Ames (University of California, Berkeley, CA, USA), and their genotypes were checked regularly. It is noteworthy that, in Ames test, simulated body fluid (SBF, PH 7.4) with concentration similar to those of human blood plasma was utilized as extraction buffer to mimic the post-implant environment [10].

A standard plate incorporation procedure was utilized in the presence and absence of Aroclor1254-induced rat liver homogenate preparation (S9). In brief, TA98 and TA100 were cultured in nutrient broth for $10 \mathrm{~h}$ at $37^{\circ} \mathrm{C}$ under agitation. Thereafter, $500 \mu \mathrm{l}$ of S9 mix (or $500 \mu \mathrm{l}$ of phosphate buffer), $100 \mu \mathrm{l}$ of different concentrations of extracts and $100 \mu \mathrm{l}$ of bacterial culture were added to $2.5 \mathrm{~mL}$ top agar and vortexed for $3 \mathrm{~s}$. Then the mixture was poured onto a minimal agar plate. The plates were incubated at $37^{\circ} \mathrm{C}$ for $48 \mathrm{~h}$. Following this, the revertant bacterial colonies on each plate were counted.

\subsection{Data Analysis}

All data were analysed using the spss (v16.0; Chicago, IL, USA). Qualitative and quantitative data were tested using the Chi-square test and Student's test, respectively. P < 0.05 was considered statistically significant.

\section{Results}

\subsection{Implanting Test}

For all of the rabbits, the insertion hole could still be found on the muscle fascia for all implants after 1, 4, and 12 weeks. After 1 week of implantation, the implants were located in a muscular pocket that was clearly separated from the surrounding tissue. At 4 weeks, fibrous tissue formation started resulting in encapsulation of the implanted material. At 12 weeks, the implants adhered tightly to the surrounding tissue, and the area of the implantation resembled the surrounding original tissue. Light micrographs of histologic sections after 1, 4, and 12 weeks of implantation are shown in Figure 2.

\subsection{Trypan Blue Assay}

Before performing the comet assay, viability of TM4 cells was estimated using trypan blue exclusion. Light microscopic examination of the cells after staining with trypan blue demonstrated stable viability over all the concentrations used for genotoxicity tests, with percent viability consistently over $90 \%$ in all samples.

\subsection{Alkaline Comet Assay}

The OTM was assayed as a measure of DNA-strand breaks in the SCGE assay. As seen in Figure 3, without affecting the cell viability, extractables of the nano-silica modified polymer composite were not found to induce significant DNA damage $(\mathrm{P}>0.05)$ at all concentrations compared to the control. Figure 4 exhibited the images of DNA damage with different extractables. 


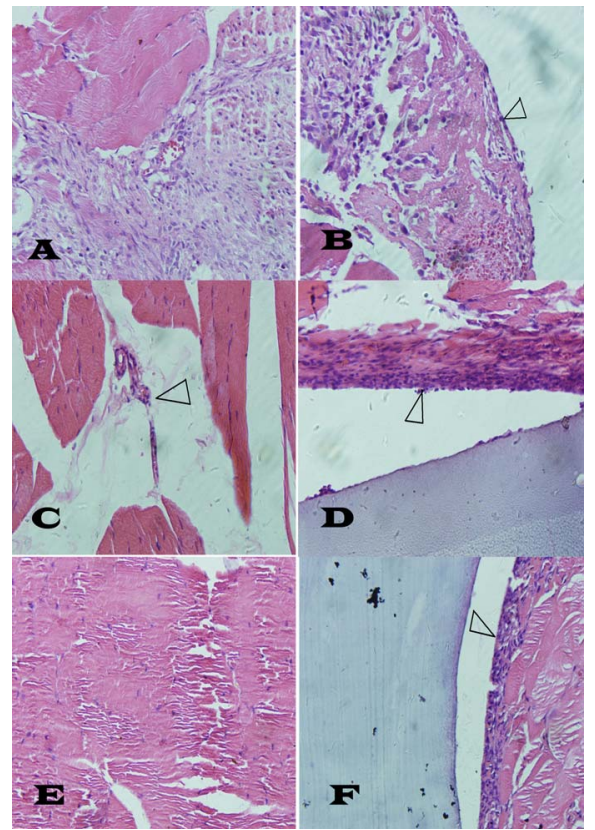

Figure 2. At 1 week, a phagocytotic and inflammatory reaction occurred (B); Similar inflammatory reaction was observed on the sham-operated side (A); At 4th week, the number of inflammatory cells decreased sharply, heterophil granulocyte disappeared, lymph cells were reduced, and compact fibrous capsule formed (D, white arrow); Small number of lymphocytes were observed on the sham-operated side (C, white arrow); At 12th week, the inflammatory reaction of the two groups had almost disappeared (E, F); Furthermore, the surrounding fibrous capsule had become more stable ( $F$, white arrow).

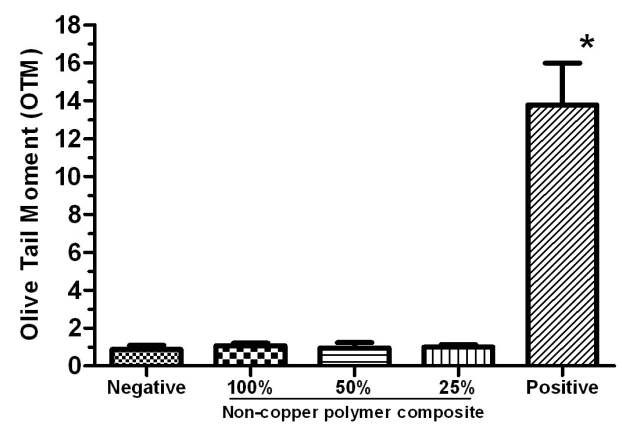

Figure 3. DNA damage as measured in comet assay in TM4

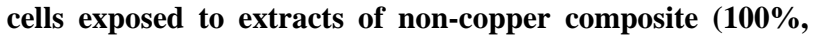
$50 \%, 25 \%$ ), the negative and positive controls. The bars represent the mean values \pm standard deviations (S.D.) of Olive tail moment (OTM). One hundred and fifty cells were assessed in each test. Statistical significance as compared to the vehicle (negative) control is indicated by asterisks. Complete growth medium: vehicle control; hydrogen peroxide: positive control (100 microM).

\subsection{Ames Test}

All the concentrations $(100 \%, 50 \%, 25 \%$, and $12.5 \%)$ of the nano-silica modified polymer composite were pre-

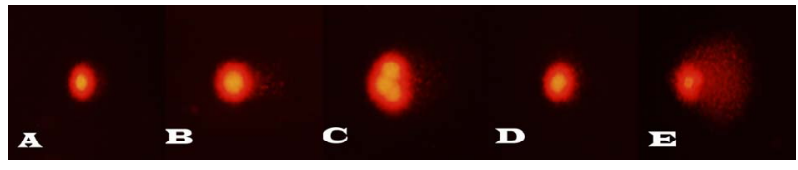

Figure 4. Representative SCGE assay images of TM4 cells, stained with ethidium bromide. (A) Negative control; (B)(D) Extracts of the non-copper composite at concentrations of $100 \%$ (B); $50 \%$ (C); $25 \%$ (D); Positive control (E): hydrogen peroxide (100 microM). Of the images captured, all extracts of the non-copper composite (B, C and D) exhibited the similar images to the negative control. But the positive control displayed the comets with unusually long tail.

pared by a serial dilution. As summarized in Table 1, the number of revertant colonies did not exceed the threshold of twice the number of the solvent control following exposure to the composite extracts in all of the concentrations in TA98, with and without S9-mix. Following treatment in the TA100 strain, no significant increase in the incidence of revertant colonies was observed at all concentrations in the presence and absence of S9-mix. As a matter of fact, comparison of mutagenicity ratio (MR) between the nano-silica modified polymer composite and the negative control indicated no significant difference at any concentration in the presence or absence of metabolic activation, but there are significant differences to the positive controls.

\section{Discussion}

The experimental biomaterials were regarded to be biocompatible if the intensity of connective reaction decreased over time. Consequently, to be considered biocompatible, at 90 days the connective tissue surrounding the implant must show a thin fibrous capsule formation surrounding the tube as well as an absence of inflammatory reaction and/or macrophages/giant cells. On the other hand, the material is considered to be non-biocompatible when a persistent inflammatory reaction occurs related to macrophages and giant cells with a thick fibrous capsule development even at 90 days after implantation. So as the result exhibited, the nano-silica modified polymer composite is histocompatible.

When the toxicity of a composite is concerned, we need to evaluate all of its major constituents. Firstly, the nanoparticles of silica was paid attention to, because it is widely used in food and biomaterials nowadays. The response of several normal fibroblast and tumor cells to varying doses of amorphous silica or composite nanoparticles of silica and chitosan was investigated [11]. A cell proliferation assay indicates that silica nanoparticles are nontoxic at low dosages but that cell viability decreases at high dosages. A lactate dehydrogenase assay indicates that high dosages of silica induce cell membrane damage [11]. Endothelial cells exposure to silica nanoparticles 
Table 1. Mutagenicity analysis of non-copper polymer composite using Ames test with S. typhimurium strains TA98 and TA100 in the absence and presence of metabolic activation.

\begin{tabular}{|c|c|c|c|c|c|c|c|c|}
\hline \multirow{2}{*}{ Treatment } & \multicolumn{2}{|c|}{ TA98 (without S9) } & \multicolumn{2}{|c|}{ TA100 (without S9) } & \multicolumn{2}{|c|}{ TA98 (with S9) } & \multicolumn{2}{|c|}{ TA100 (with S9) } \\
\hline & Rev/plate ${ }^{a}$ & $\mathrm{MR}^{\mathrm{b}}$ & Rev/plate & MR & Rev/plate & MR & Rev/plate & MR \\
\hline \multicolumn{9}{|c|}{ Non-copper polymer composite } \\
\hline $100 \%$ & $34 \pm 1.5$ & 1.58 & $257 \pm 14$ & 1.47 & $28 \pm 1$ & 1.43 & $212 \pm 9$ & 1.46 \\
\hline $50 \%$ & $27 \pm 1$ & 1.26 & $203 \pm 8$ & 1.16 & $24 \pm 0.5$ & 1.23 & $165 \pm 12$ & 1.14 \\
\hline $25 \%$ & $23 \pm 0.5$ & 1.07 & $186 \pm 11$ & 1.07 & $21 \pm 2$ & 1.08 & $150 \pm 5$ & 1.03 \\
\hline $12.5 \%$ & $24 \pm 1$ & 1.12 & $172 \pm 6$ & 0.99 & $22 \pm 1$ & 1.13 & $138 \pm 3$ & 0.95 \\
\hline c4-NOPD $(100 \mu \mathrm{g} / \mathrm{mL})$ & $475 \pm 8$ & 22.1 & & & & & & \\
\hline $\mathrm{NA}(15 \mu \mathrm{g} / \mathrm{mL})$ & & & $2998 \pm 6$ & 17.2 & & & & \\
\hline $2-\mathrm{AF}(200 \mu \mathrm{g} / \mathrm{mL})$ & & & & & $143 \pm 2$ & 7.33 & $937 \pm 3$ & 6.45 \\
\hline
\end{tabular}

${ }^{a}$ Number of revertants/plate: mean of three independent experiments, in triplicate \pm S.D; ${ }^{b}$ The mutagenicity ratio (MR) was calculated by dividing the mean value of the revertant counts through the mean values of vehicle control (SBF). A test sample was considered to be mutagenic if MR $\geq 2$ with an observed concentration-dependent relationship; ${ }^{\mathrm{C}}$ Positive controls: 4-NOPD: 4-Nitro-o-phenylenediamine; NA: sodium azide; 2-AF: 2-aminofluorene.

causes cytotoxic damage and a decrease in cell survival in the EAHY926 cell line in a dose-related manner [12]. Cytotoxicity profile of silica nanoparticles has received experimental support in different model cell lines, which was considered to be the result of size-/dose-dependent effect and oxidative stress provoked by these particles [13]. Whereas Morishige T. et al. [14] did not observe cell death when treated with silica nanoparticles (30-, 50-, 70-nm). On the other hand, a recent study reported that amorphous silica nanoparticles elicited chromosomal aberrations and gene mutations [15]. However, there are conflicting reports such as the one which did not observe silica nanoparticles-induced genotoxic hazard using a Comet assay [16]. Overall, the available experimental data do not fully characterize the cytotoxic and genotoxic potentials of amorphous silica nanoparticles by virtue of these discrepancies. In a recent study, no significant amorphous silica nanoparticles-related cyto- and genotoxic response was observed, which may be, in part, due to relatively low dosage loaded and sol-gel-derived silica that minimize silica dissolution and improve the biocompatibility [17]. The silica nanoparticles we used were cross-linked with PVA, the dosage was low, and the gravitational force between molecules also may limit their effluence from the complex, possible explaining why no significant cytotoxicity and genotoxicity were observed in this nano-silica modified polymer composite. In conclusion, results from the biocompatibility and in vitro genotoxicity tests of the non-copper composite demonstrated that this nano-silica modified polymer composite is histocompatible and non-genotoxic. As it is as the same configuration and function as the copper-containing composite IVD which has exhibited effective contracep- tive effects, the nano-silica modified non-copper polymer composite IVD would be a safe and promising alternative to the operation of vasectomy.

\section{Acknowledgements}

We greatly appreciated the help and support giving by Mr Chunyou Chen, Xianing Huang, Chuangang Fan, Li Tan and Guodong Zhao for their assistance in this project.

\section{REFERENCES}

[1] L. Song, Y. Gu, W. Lu, X. Liang and Z. Chen, "A Phase II Randomized Controlled Trial of a Novel Male Contraception, an Intra-Vas Device," International Journal of Andrology, Vol. 29, No. 4, 2006, pp. 489-495. doi:10.1111/j.1365-2605.2006.00686.x

[2] Z. L. Chen, X. B. Huang, J. P. Suo, J. Li and L. Sun, "The Contraceptive Effect of a Novel Filtering-Type NanoCopper Complex/Polymer Composites Intra-Vas Device on Male Animals," International Journal of Andrology, Vol. 33, No. 6, 2010, pp. 810-817. doi:10.1111/j.1365-2605.2009.01028.x

[3] C. A. Grillo, M. A. Reigosa and M. F. Lorenzo de Mele, "Effects of Copper Ions Released from Metallic Copper on CHO-K1 Cells," Mutation Research, Vol. 672, 2008, pp. $45-50$.

[4] C. A. Grillo, M. A. Reigosa and M. A. de Mele, "Does Over-Exposure to Copper Ions Released from Metallic Copper Induce Cytotoxic and Genotoxic Effects on Mammalian Cells?" Contraception, Vol. 81, No. 4, 2010, pp. 343-349. doi:10.1016/j.contraception.2009.12.003

[5] D. Prá, S. I. Franke, R. Giulian, M. L. Yoneama, J. F. Dias, B. Erdtmann, et al., "Genotoxicity and Mutagenicity of Iron and Copper in Mice," Biometals, Vol. 21, No. 
3, 2008, pp. 289-297. doi:10.1007/s10534-007-9118-3

[6] W. Strober, "Trypan Blue Exclusion Test of Cell Viability," Current Protocols in Immunology, 2001, Appendix 3: Appendix 3B.

[7] R. R. Tice, E. Agurell, D. Anderson, B. Burlinson, A. Hartmann, H. Kobayashi, et al., "Single Cell Gel/Comet Assay: Guidelines for in Vitro and in Vivo Genetic Toxicology Testing," Environmental and Molecular Mutagenesis, Vol. 35, No. 3, 2000, pp. 206-221.

doi:10.1002/(SICI)1098-2280(2000)35:3<206::AID-EM8 $>3.0 . \mathrm{CO} ; 2-\mathrm{J}$

[8] K. Końca, A. Lankoff, A. Banasik, H. Lisowska, T. Kuszewski and S. Góźdź, "A Cross-Platform Public Domain PC Image-Analysis Program for the Comet Assay," Mutation Research, Vol. 534, No. 1, 2003, pp. 15-20.

[9] P. L. Olive and J. P. Banáth, "The Comet Assay: A Method to Measure DNA Damage in Individual Cells," Nature Protocols, Vol. 1, 2006, pp. 23-29. doi:10.1038/nprot.2006.5

[10] C. Combes and C. Rey, "Adsorption of Proteins and Calcium Phosphate Materials Bioactivity," Biomaterials, Vol. 23, No. 13, 2002, pp. 2817-2823. doi:10.1016/S0142-9612(02)00073-X

[11] J. S. Chang, K. L. Chang, D. F. Hwang and Z. L. Kong, "In Vitro Cytotoxicitiy of Silica Nanoparticles at High Concentrations Strongly Depends on the Metabolic Activity Type of the Cell Line," Environtal Science \& Technology, Vol. 41, No. 6, 2007, pp. 2064-2068.

[12] D. Napierska, L. C. Thomassen, V. Rabolli, D. Lison, L.
Gonzalez, M. Kirsch-Volders, et al., "Size-Dependent Cytotoxicity of Monodisperse Silica Nanoparticles in Human Endothelial Cells," Small, Vol. 5, No. 7, 2009, pp. 846-853. doi:10.1002/smll.200800461

[13] H. Nabeshi, T. Yoshikawa, K. Matsuyama, Y. Nakazato, A. Arimori, M. Isobe, et al., "Size-Dependent Cytotoxic Effects of Amorphous Silica Nanoparticles on Langerhans Cells," Pharmazie, Vol. 65, No. 3, 2010, pp. 199201.

[14] T. Morishige, Y. Yoshioka, H. Inakura, A. Tanabe, X. Yao, S. Tsunoda, et al., "Cytotoxicity of Amorphous Silica Particles against Macrophage-Like THP-1 Cells Depends on Particle-Size and Surface Properties," Pharmazie, Vol. 65, No. 8, 2010, pp. 596-599.

[15] M. V. Park, H. W. Verharen, E. Zwart, L. Hernandez, J. van Benthem, A. Elsaesser, et al., "Genotoxicity Evaluation of Amorphous Silica Nanoparticles of Different Sizes Using the Micronucleus and the Plasmid lacZ Gene Mutation Assay," Nanotoxicology, Vol. 5, No. 2, 2011, pp. 168-181.

[16] C. A. Barnes, A. Elsaesser, J. Arkusz, A. Smok, J. Palus, A. Leśniak, et al., "Reproducible Comet Assay of Amorphous Silica Nanoparticles Detects No Genotoxicity," Nano Letters, Vol. 8, No. 9, 2008, pp. 3069-3074. doi:10.1021/n1801661w

[17] A. Nieto, S. Areva, T. Wilson, R. Viitala and M. ValletRegi, "Cell Viability in a Wet Silica Gel," Acta Biomaterialia, Vol. 5, No. 9, 2009, pp. 3478-3487. doi:10.1016/j.actbio.2009.05.033 